\title{
Large Porites microatoll found by aerial survey at Sesoko Island, Okinawa, Japan
}
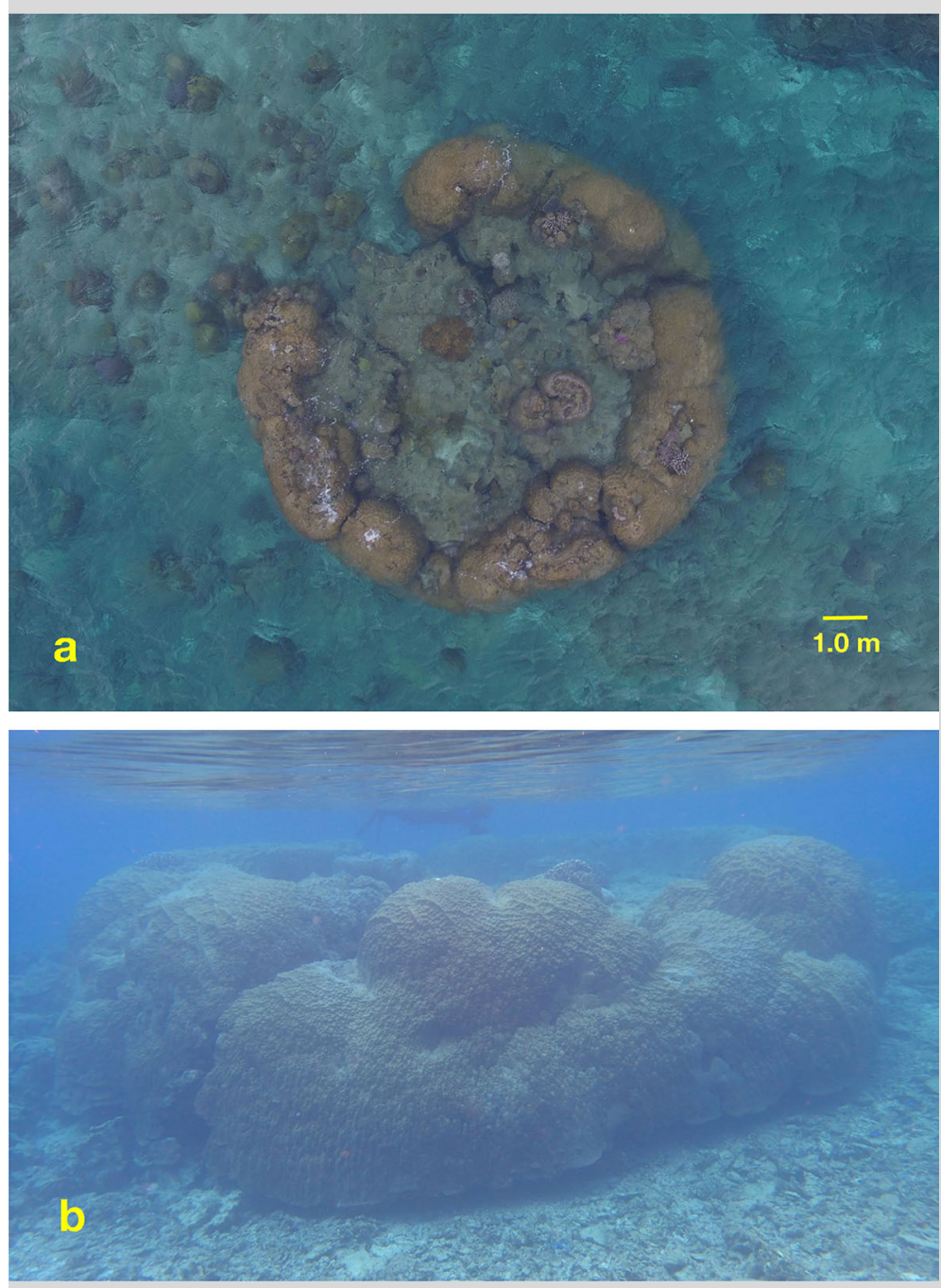

Fig. 1 Large Porites microatoll at Sesoko Island, Okinawa, Japan. a Aerial photo taken from an altitude of $11 \mathrm{~m}$ at near low tide. The top of the microatoll is near the sea surface. b Underwater view Stoddart DR, Scoffin TP (1979) Microatolls: review of form, origin and terminology. Atoll Res Bull 224:1-17

Woodroffe CD, Webster JM (2014) Coral reefs and sea-level change. Mar Geol 352:248-267

I. Takeuchi $(\bowtie)$

Graduate School of Agriculture, Ehime University, Matsuyama, Ehime, Japan

e-mail: takeuchi@agr.ehime-u.ac.jp

H. Yamashiro

Sesoko Station, Tropical Biosphere Research Center, University of the Ryukyus, Motobu, Okinawa, Japan

Received: 7 June 2017/Accepted: 20 September 2017/Published online: 3 October 2017

(C) Springer-Verlag GmbH Germany 2017
The hermatypic coral, Porites, grows into a large, solid or flat-topped microatoll, typically comprised of a single coral colony, usually round, and with a flat or concave upper surface devoid of living polyps (Stoddart and Scoffin 1979). The largest reported Porites microatoll in fossil records from the Pacific and southern China was ca. $9 \mathrm{~m}$ in diameter (Woodroffe and Webster 2014).

An extremely large microatoll of $P$. australiensis Vaughan, 1918 (Fig. 1) was found ca. $150 \mathrm{~m}$ offshore from the southern coast of Sesoko Island, Okinawa, Japan $\left(26^{\circ} 37^{\prime} 39.47^{\prime \prime} \mathrm{N}, 127^{\circ} 51^{\prime} 39.77^{\prime \prime} \mathrm{E}\right)$ by aerial surveys in March-April 2017 using a drone (Phantom 3 Professional; DJI Co. Ltd, Guangdong, China), improved to be water resistant by Japan Circuit Co. Ltd (Kanagawa, Japan). Sesoko Island is located northwest of Okinawa Island in the East China Sea and is thus protected from Pacific typhoons. The microatoll is located east of the fringing reef from the south end the island on a slanted sandy to pebble bottom (ca. $1.2-3.0 \mathrm{~m}$ deep at near mean low-water springs). The reef protects the microatoll from ocean waves from the East China Sea. The tidal range of the site is ca. $2.3 \mathrm{~m}$.

The length of the longest axis is $11.1 \mathrm{~m}$, and the circumference is $33.7 \mathrm{~m}$. The living part of the microatoll (on the outer edge) is circular and $0.5-1.5 \mathrm{~m}$ in width. The estimated growth rate of $P$. australiensis at Sesoko Island is 2.6-10.8 $\mathrm{mm} \mathrm{yr}^{-1}$ (Hayashi et al. 2013). At this growth rate, the age of the microatoll is between 500 and $2100 \mathrm{yr}$. The stable environment at the site could lead to such longevity. Our study highlights the usefulness of drone surveys in the study of coral reef topography.

Acknowledgements Comments from Dr. A. Suzuki improved the manuscript. The study was partially supported by JSPS KAKENHI (No. 15K12253).

\section{References}

Hayashi E, Suzuki A, Nakamura T, Iwase A, Ishimura T, Iguchi A, Sakai K, Okai T, Inoue M, Araoka D, Murayama S, Kawabata H (2013) Growth-rate influences on coral climate proxies tested by a multiple colony culture experiment. Earth Planet Sci Lett 362:198-206 